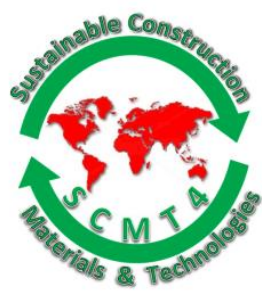

SCMT4

Las Vegas, USA, August 7-11, 2016

\title{
Development of Air Inflow Model for Airtightness Performance Evaluation of Concrete Tube Structures with Cracks
}

\author{
Jaegu Choi ${ }^{1 \mathrm{a}}$, Oneil Han ${ }^{1 \mathrm{~b}}$, and Joonam Park ${ }^{* 2}$ \\ ${ }^{1}$ Department of Civil Engineering, Yonsei University, Republic of Korea, \\ ${ }^{1 a}$ Email: 〈cig1204@yonsei.ac.kr>, ${ }^{1 b}$ Email: 〈oneilhan@yonsei.ac.kr>. \\ ${ }^{2}$ Department of Civil and Environmental Engineering, Wonkwang University, Republic of Korea, \\ Email: <joonam.park@gmail.com>.
}

\begin{abstract}
Vacuum tube transportation system is considered to be one of the most effective alternative transportation systems that can substitute the existing aviation system. Ensuring the airtightness of the vacuum tube system is therefore the most critical requirement of the infrastructure. This study proposes a model for airtightness performance evaluation of concrete vacuum tube structures with cracks. Several crack models are reviewed first and a simplified model for estimation of the total crack area is established. A hypothetical model that describes the pressure behavior inside a concrete vacuum tube subjected to cracks due to external loadings is developed. The model developed is expected to provide a basis for an experimental study to be performed in the near future. Based on both the experimental test and the analytical model developed, the relationship between the crack propagated in the concrete vacuum tube structures and its equivalent system air permeability is established.
\end{abstract}

\section{INTRODUCTION}

Super speed tube train (SSTT) is considered recently as an alternative mass transportation system that could substitute the current aviation system (Figure 1). The main idea of SSTT is to maintain the air pressure inside a tubed tunnel, which is also called a vacuum tube, much lower than the atmospheric pressure, such that the trains that operate in the tube undergo much less air resistance. According to recent studies (Cassat et al. 2003; KRRI 2009) the practical operating speed of the train could reach up to $700 \mathrm{~km} / \mathrm{h}$ when the pressure inside the tube structures is maintained at ten percent of the atmospheric pressure. Materials with low air permeability must be used for construction of the vacuum tube structure. The discontinuous regions such as joints and connections should also be carefully designed considering the system airtightness. Park et al. (2013) investigated the applicability of concrete as a material for vacuum tube systems in terms of its airtightness. The air permeability of the concrete material was experimentally evaluated and the pressure change inside a vacuum tube structure was analytically estimated. The system airtightness was also evaluated both analytically and experimentally considering the effect of the existence of discontinuous regions such as joints. This approach, however, was not considering the effect of the external loadings applied to the tube structures. Concrete structures are 
subject to cracks under service loadings. The cracks that develop due to external loadings may accelerate air inflow into a vacuum structure (Okamoto et al. 1995). For design purpose the relations between loadings and cracks and between cracks and system airtightness should be established. This study develops an analytical model for estimation of the air inflow through cracks on a concrete vacuum tube structure that occur due to external loadings. It is assumed that the inside pressure of a concrete vacuum tube structure is initially dropped down to ten percent of the atmospheric pressure. It is also assumed that cracks occur on the structure due to specified external loadings. A differential equation is then derived for description of the pressure change inside the tube structure over time, which is directly dependent upon the air inflow into the cracks. The model is developed such that it could be calibrated by performing an experimental test which will be conducted in a following study.
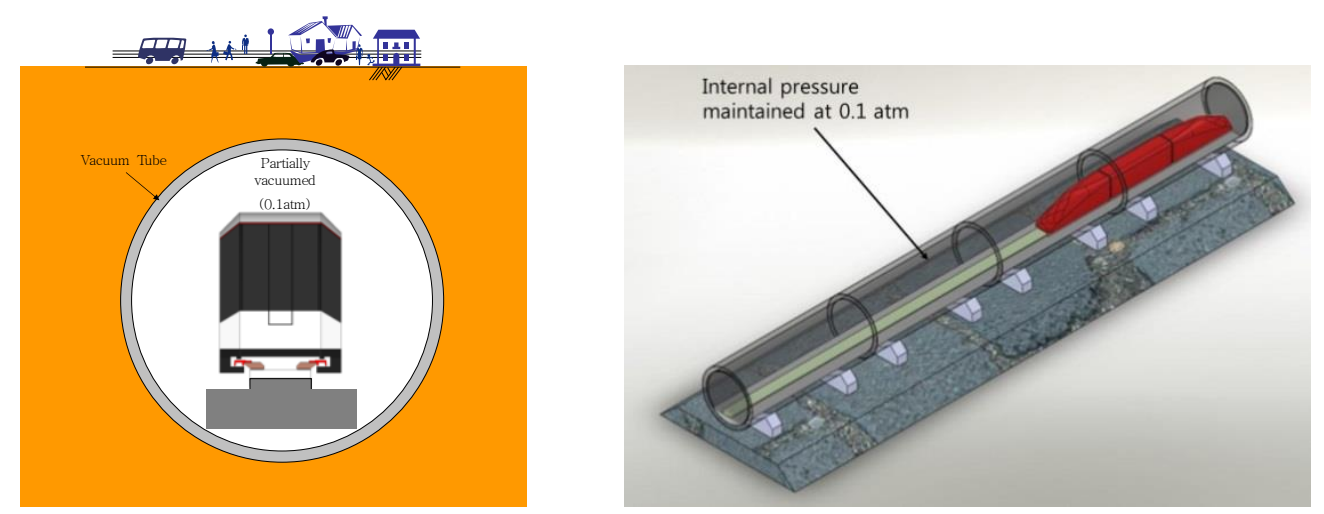

Figure 1. Super speed tube train (SSTT) system

\section{SIMPLIFIED MODEL FOR AIR INFLOW THROUGH CRACKS}

As briefly mentioned in the previous section, cracks that form on the concrete vacuum tube structure could seriously affect the system airtightness. From the design point of view it is very important to quantitatively anticipate the amount of air inflow into the vacuum tube structure with time. Many design variables such as the capacity and spacing of the vacuum pumps and their operating time, and the operating speed of trains should be determined with a systemic consideration of the system airtightness (Nam 2010; Park et al. 2013). A number of crack models for concrete structures were developed by numerous researchers (e.g., Frosch 1999; Gilbert 2005). Although a variety of differences exist in the assumptions and approaches of the models, most of the crack models basically provide the width, length, and the spacing of the cracks developed on the structure due to a specified loading case. Figure 2 schematically shows the development of cracks on a tube structure due to external loadings. The flexural cracks would be developed under the loadings as shown in the figure. Each crack could be defined with the widths and lengths. If the shape of the crack is assumed as a diamond shape as in Figure(b), total area of the cracks, $\mathrm{A}_{\mathrm{ck}}$, is calculated as:

$\mathrm{A}_{\mathrm{ck}}=\frac{1}{2} \sum_{\mathrm{i}=1}^{\mathrm{n}} \mathrm{w}_{\mathrm{i}} \mathrm{l}_{\mathrm{i}}$

where, $w_{i}$ and $l_{i}$ are the width and the length of $i$-th crack measured inside the tube, respectively. It should be noted that this model is used in this study for simplicity but could be calibrated through experiments and more refined analytical models. 


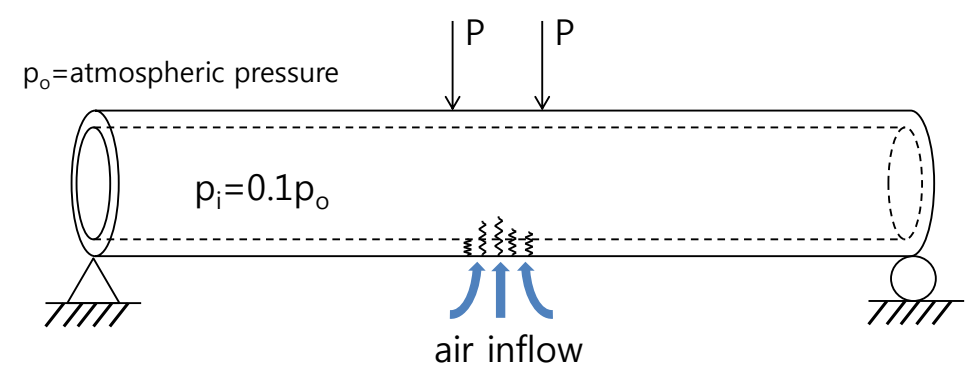

(a) Flexural loading applied to a tube structure
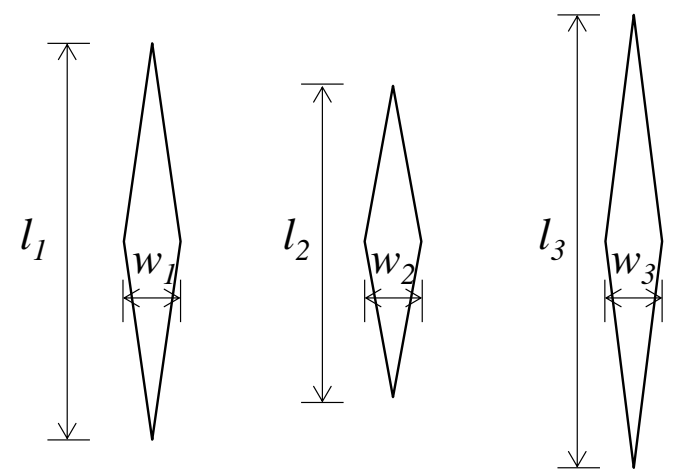

(b) Simplification of cracks developed

\section{Figure 2. Crack development due to external loading}

Error! Reference source not found. shows a simple concept of air inflow into a vacuum structure with cracks. Bernoulli's equation is utilized in order to estimate the pressure change inside the tube structure with crack. For the air inflow the following relation is established.

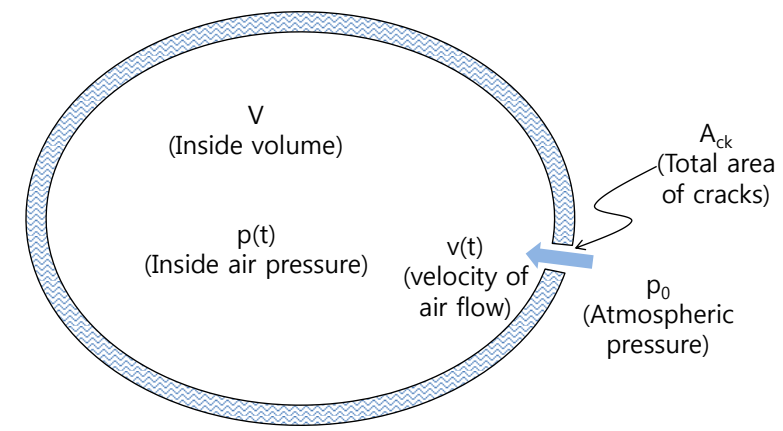

Figure 3. Air inflow into cracked area

$\mathrm{p}_{\mathrm{o}}+\frac{1}{2} \rho \cdot \mathrm{v}_{\mathrm{o}}{ }^{2}=\mathrm{p}(\mathrm{t})+\frac{1}{2} \rho \cdot(\mathrm{v}(\mathrm{t}))^{2}$

where, $p_{o}$ and $v_{o}$ are the atmospheric pressure and the velocity of the air outside the structure, respectively, $\rho$ is the density of the air, $p(t)$ is the pressure inside the structure at time $t$, and $v(t)$ is the velocity of the air inflow measured inside the crack. $A s v_{0}=0, v(t)$ can be estimated as 
$v(t)=\sqrt{\frac{2\left(p_{o}-p(t)\right)}{\rho}}$

If the temperature inside and outside the structure are assumed to be equal, the flow rate, $Q(t)$ and the pressure inside the structure, $\mathrm{p}(\mathrm{t})$ have a following relation.

$\mathrm{p}_{\mathrm{o}} \cdot \mathrm{Q}(\mathrm{t})=\frac{\mathrm{dp}(\mathrm{t})}{\mathrm{dt}} \mathrm{V}$

Where $\mathrm{V}$ is the volume of the inside of the structure and $\mathrm{Q}(\mathrm{t})=\mathrm{A}_{\mathrm{ck}} \cdot \mathrm{v}(\mathrm{t})$. Eq.(3) then becomes a differential equation

$\frac{d p(t)}{d t}=\frac{p_{o}}{V} \cdot Q(t)=\frac{p_{o} \cdot A_{c k}}{V} \cdot v(t)=\frac{p_{o} \cdot A_{c k}}{V} \cdot \sqrt{\frac{2\left(p_{o}-p(t)\right)}{\rho}}$

On solving the differential equation with an initial condition that $p(0)=0.1 p_{o}$, the pressure inside the structure with time is estimated as

$\mathrm{p}(\mathrm{t})=\mathrm{p}_{\mathrm{o}}-\left[\sqrt{0.9 \mathrm{p}_{\mathrm{o}}}-\frac{\mathrm{p}_{\mathrm{o}} \cdot \mathrm{A}_{\mathrm{ck}}}{\sqrt{2 \rho} \cdot \mathrm{V}} \cdot \mathrm{t}\right]^{2} \quad\left(\because \mathrm{t} \leq \frac{\mathrm{V} \cdot \sqrt{1.8 \mathrm{p}_{\mathrm{o}} \cdot \rho}}{\mathrm{p}_{\mathrm{o}} \cdot \mathrm{A}_{\mathrm{ck}}}\right)$

Equation (5) indicates that the pressure inside a vacuum structure rises quadratically as time increases. Figure 4(a) shows how the inside pressure changes with time for different values of $A_{c k}$ for a tube structure with a circular section with a diameter of $5.0 \mathrm{~m}$. It is also assumed that the inside pressure is initially dropped down to 10 percent of the atmospheric pressure. The pressure rises more rapidly as the total area of cracks, $A_{c k}$, increases. Figure 4(b) shows the relation between $A_{c k}$ and the estimated time for the inside pressure to reach $0.2 \mathrm{p}_{\mathrm{o}}, \mathrm{T}_{\mathrm{cp}}$. It would be rational to assume that the vacuum pumps reactivate when the inside pressure rises up to a specified threshold value, $\mathrm{p}_{\mathrm{cp}}$, which is not much larger than the initial pressure level. This pressure limit for operation should be determined with a consideration of the train propulsion and the vacuum pump capacity. 20 percent of the atmospheric pressure is assumed for the limit pressure in this study. The analysis result shows that for the given configuration of the tube structure, for example, total area of cracks must be controlled under $7.0 \times 10^{-7} \mathrm{~m}^{2}$ in order to keep $\mathrm{T}_{\text {cr }}$ longer than two hours. On the other hand, for a case that Ack is larger than $3.0 \times 10^{-6} \mathrm{~m}^{2} \mathrm{~T}_{\mathrm{cr}}$ is estimated shorter than 0.5 hours. It is apparent that time to reach the limit pressure, or $T_{\mathrm{cp}}$ is significantly sensitive to the total area of cracks as it is inversely proportional to $\mathrm{A}_{\mathrm{ck}}$ as

$\operatorname{Tcp}=\frac{\sqrt{2 \rho} \cdot \mathrm{V} \cdot\left(\sqrt{0.9 \mathrm{p}_{\mathrm{o}}}-\sqrt{0.8 \mathrm{p}_{\mathrm{o}}}\right)}{\mathrm{p}_{\mathrm{o}} \cdot \mathrm{A}_{\mathrm{ck}}}=0.07673 \sqrt{\frac{\rho}{\mathrm{p}_{o}}} \cdot \frac{\mathrm{V}}{\mathrm{A}_{\mathrm{ck}}}$ 
Experimental study should follow in order to refine the model developed in this study. In reality, detecting and measuring concrete cracks that occur on a concrete structure is not an easy task. The model developed can also be used for calibration of the concrete crack models, as it can estimate the total area of cracks by back substituting Eq. (5).

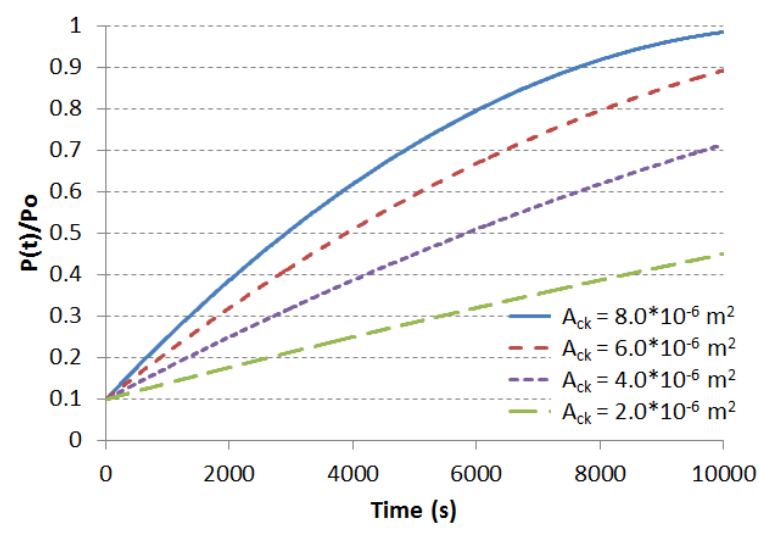

(a) Pressure behaviors with various crack area values

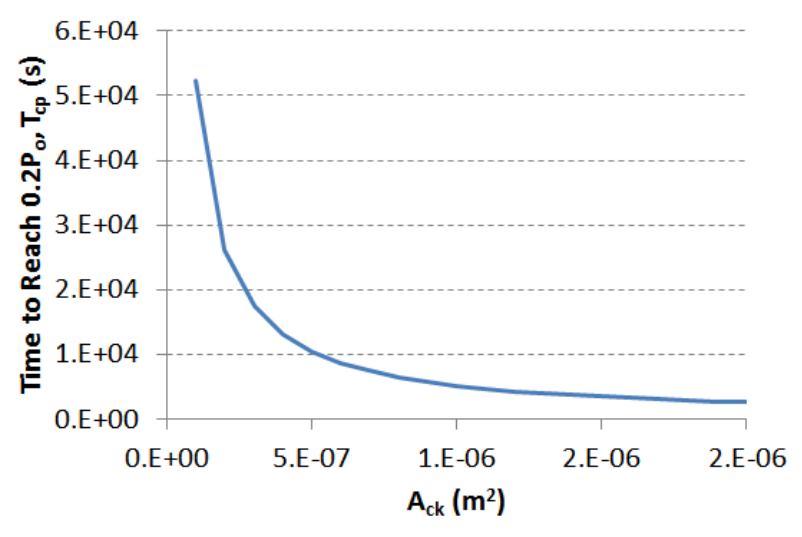

(b) Time to reach $0.2 p_{o}$ upon $A_{c k}$

Figure 4. Pressure change with various values of $\mathbf{A}_{\mathrm{ck}}$

\section{SUMMARY}

An analytical model that anticipates the pressure change inside a vacuum tube structure due to cracks is developed by solving a differential equation. Bernoulli's equation is utilized for derivation of the differential equation that describes the pressure behavior inside a vacuum tube structure. It appears from the model that the pressure rise in a tube structure with cracks has quadratic relation with increasing time. In addition, time to reach the limit pressure is significantly sensitive to the total area of cracks as it is inversely proportional to the total area of cracks. It is expected that the model developed in this study can also be used for calibration of the concrete crack models in conjunction with an experimental work.

\section{ACKNOWLEDGEMENTS}

This work was supported by the National Research Foundation of Korea (NRF) grant funded by the Korea government (MSIP) (No. 2014R1A2A2A01007654). The opinions, findings, conclusions, and recommendations expressed in this paper are those of the authors and do not necessarily reflect those of the sponsor.

\section{REFERENCES}

Cassat A., Bourquin V., Mossi M., Badoux M., Vernez D., Jufer M., Macabrey N., and Rossel P. (2003) SWISSMETRO - Project Development Status, International Symposium on Speed-up and Service Technology for Railway and Maglev Systems 2003 (STECH '03), pp. 453-410, Tokyo, Japan.

Frosch R.J. Another look at cracking and crack control in reinforced concrete. ACI Struct J 1999;96(3):437-42. 
Gilbert R.I. Time-dependent cracking and crack control in reinforced concrete structures. In: Serviceability of concrete, SP-225. Farmington Hills (MI): American Concrete Institute; 2005. p. 22340.

Korea Railroad Research Institute (2009) Development of New Infra-structure Technology for Ultra High Speed Tube Train (PK09001C), Project Report.

Nam S.W. (2010) "Parametric study on the capacity of vacuum pump for tube structure", Journal of the Korean Society for Railway, 13(5), pp. 516-520, http://dbpia.co.kr/view/ar_view.asp?arid=1543546

Okamoto, K., Hayakawa, S., Kamimura, R. (1995), "Experimental study of air leakage from cracks in reinforced concrete walls", Nuclear Engineering and Design, 156(1/2), pp.159-165, http://dx.doi.org/10.1016/0029-5493(94)00941-Q

Park J., Cho J., Park H-J. (2014), "Probabilistic estimation of airtightness of performance of concrete vacuum tube structures", 10th International Symposium on High Performance Concrete - Innovation \& Utilization, September 16-18, Beijing, China

Park J., Kim L-H., Nam S-W., and Yeo I. (2013) "Performance Evaluation of Airtightness in Concrete Tube Structures for Super-Speed Train Systems", Magazine of Concrete Research, 65(9), pp. 535-545, DOI: $10.1680 /$ macr.12.00161 